\title{
Transition of microbial community structures after development of membrane fouling in membrane bioreactors (MBRs)
}

\author{
Yuya Sato ${ }^{*}$ (D), Yan-Jie Zhao ${ }^{\dagger}$, Tomoyuki Hori, Tomo Aoyagi, Tomohiro Inaba, Hidenobu Aizawa, Atsushi Ogata \\ and Hiroshi Habe
}

\begin{abstract}
Although membrane fouling is a major issue when operating membrane bioreactors (MBRs), information regarding MBR performance and the sludge microbiome after the development of fouling remains limited. For the present study, two MBRs were operated for approximately 1 month under conditions of membrane fouling to investigate the effects of highly stressed environments on the sludge microbiome. After the development of fouling, a Collimonasrelated operational taxonomic unit (OTU) was highly dominant in both reactors (relative abundances were 63\%) and this predomination caused a precipitous decline in the diversity indices of the sludge microbiomes. Because the excessive predomination by limited numbers of OTUs can lead to reductions in the adaptability to environmental changes, monitoring microbial diversity may be a valuable indicator for maintaining the robustness of a sludge microbiome. While, the decrease in the abundance of the Collimonas-related OTU resulted in the predomination of distinct microorganisms in each of the reactors despite being operated under the same conditions; this finding indicates existence of strong pressure to perturb the microbiomes. Detailed analyses suggested that the availability of terminal electron acceptors and competitive interactions between microbes via the secretion of extracellular proteins appeared to differentiate the structures of the respective microbial communities. During the extracellular proteins were secreted in the sludge, considerable portion of microbes were dead and large amounts of biomolecules seemed to be released; resultantly facilitated the predomination of fermentative anaerobes in one reactor as they use organic substances but not inorganic terminal electron acceptors to generate ATP under anaerobic conditions.
\end{abstract}

Keywords: Membrane bioreactor, High-throughput sequencing, Microbial community, Membrane fouling, Activated sludge

\section{Introduction}

Activated sludge has been used around the world for wastewater treatment for over 100 years and represents an important and familiar biotechnology in modern societies (Li et al. 2015; Sheik et al. 2014). While, activated sludge is a complex microbial community composed of more than thousand kinds of microorganisms including

\footnotetext{
*Correspondence: yuya-satou@aist.go.jp

†Yuya Sato and Yan-Jie Zhao equally contributed to this work Environmental Management Research Institute, National Institute of Advanced Industrial Science and Technology (AIST), 16-1 Onogawa, Tsukuba, Ibaraki 305-8569, Japan
}

bacteria, archaea, protozoa, metazoa, and viruses (Albertsen et al. 2013; Inaba et al. 2018; Wuet al. 2019); this complexity has impeded our precise understanding of the characteristics of activated sludge (Griffin and Wells 2017). Previous studies have identified the constituent members of the sludge microbiome and revealed a close relationship between the structure of a microbial community and the treatment performance of activated sludge (Xia et al. 2018; Navarro et al. 2016; Sato et al. 2016b). However, a microbial population can be easily altered in response to environmental changes and, thus, it is challenging to operate an activated sludge bioreactor 
with a suitable microbiome over a long-term period in a stable manner (Vuono et al. 2015; Narihiro et al. 2019; Sato et al. 2019).

Membrane bioreactors (MBRs) combine the activated sludge process and membrane filtration and have become more popular in recent years because they offer several advantages over the conventional activated sludge process; i.e., high-quality effluent and a small footprint (LeClech 2010). However, a major drawback associated with MBRs is the occurrence of membrane fouling, which significantly reduces membrane performance and increases maintenance and operation costs. Although various biological and physicochemical indicators that can forecast membrane fouling have been evaluated (Inaba et al. 2017; Wang et al. 2009), almost all studies investigating this issue were performed prior to the development of membrane fouling. Therefore, information regarding the sludge microbiome after membrane fouling remains limited despite the fact that these unfavorable operational conditions are conceivable in practice. It can be predicted that the activated sludge microorganisms would be highly stressed during the operation of an MBR with a fouled membrane because undegraded organic compounds in wastewater can remain inside the sludge for long periods due to a reduced effluent rate and increases in the organic loading rate within the system (Inaba et al. 2018). Together, these factors may result in strong pressure that can perturb microbial populations in the activated sludge (Sato et al. 2016b, c; Vuono et al. 2015).

The present study operated two pilot-scale MBRs with excessively high flow rates to facilitate the development of membrane fouling. Subsequently, the MBRs were operated with fouled membranes for approximately 1 month to investigate the effects of a highly stressed environment on the sludge microbiome. In this report, the obtained microbiome data are comparatively discussed with physicochemical data regarding MBR performance to further assess previously unknown indicators of decline in MBR performance.

\section{Materials and methods}

\section{Operational conditions of the pilot-scale MBRs}

For the present study, two replicate bioreactors with 230-liter volumes were operated under the same conditions in which a membrane module with a $0.24-\mathrm{m}^{2}$ flat polyacrylonitrile membrane $(0.07 \mu \mathrm{m}$ pore size, $\mathrm{M}$-fine, Awa Paper Mfg. Co.; Tokushima, Japan) was submerged in the reaction tank (Sato et al. 2015). The flow rates of both the input wastewater and the output membrane-filtered treated water were initially set to 5761 day $^{-1}$, which resulted in a hydraulic retention time of 0.4 days. The return sludge from the third to the first compartment had a flow rate of $115 \mathrm{l} \mathrm{day}^{-1}$, the membrane filtration was performed with a cycle of permeate extraction for $9 \mathrm{~min}$ and a pause for $1 \mathrm{~min}$, and, to mix the activated sludge and control dissolved oxygen (DO) levels, air was provided through an air diffuser set at the bottom of each compartment at a flow rate of $12.5-30.01 \mathrm{~min}^{-1}$. The activated sludge in the present study was obtained from a municipal wastewater treatment plant (Kinu Aquastation; Ibaraki, Japan) and the initial mixed liquor suspended solids (MLSS) concentration was approximately $6000 \mathrm{mg} \mathrm{l}^{-1}$; no sludge was withdrawn from the reactor during the operation.

The concentration of the inlet synthetic wastewater was set at $450 \mathrm{mg}$ chemical oxygen demand (COD) $\mathrm{l}^{-1}$ (1130 total organic carbon [TOC] $\mathrm{mg} \mathrm{l}^{-1}$ ) by diluting the concentrated synthetic wastewater solution with tap water, and contained $\mathrm{CH}_{3} \mathrm{COONa}\left(2.65 \mathrm{~g} \mathrm{l}^{-1}\right)$, $\mathrm{NH}_{4} \mathrm{Cl}\left(0.376 \mathrm{~g} \mathrm{l}^{-1}\right), \mathrm{KH}_{2} \mathrm{PO}_{4}\left(0.109 \mathrm{~g} \mathrm{l}^{-1}\right)$, and peptone $\left(0.706 \mathrm{~g} \mathrm{l}^{-1}\right)$ as well as the trace elements $\mathrm{FeCl}_{3} \cdot 6 \mathrm{H}_{2} \mathrm{O}$ $\left(0.782 \mathrm{mg} \mathrm{l}^{-1}\right), \mathrm{CaCl}_{2}\left(1.56 \mathrm{mg} \mathrm{l}^{-1}\right), \mathrm{MgSO}_{4}\left(1.56 \mathrm{mg} \mathrm{l}^{-1}\right)$, $\mathrm{KCl}\left(1.56 \mathrm{mg} \mathrm{l}^{-1}\right)$, and $\mathrm{NaCl}\left(1.56 \mathrm{mg} \mathrm{l}^{-1}\right)$. The organic loading rate was calculated to $1125 \mathrm{mg} \mathrm{COD} \mathrm{l}^{-1}$ day $^{-1}$.

To induce membrane fouling, the reactors were operated at a flow rate of $100 \mathrm{l} \mathrm{m}^{-2} \mathrm{~h}^{-1}$, which is excessively higher than the flux value of approximately $20 \mathrm{l} \mathrm{m}^{-2} \mathrm{~h}^{-1}$ that was previously reported to be necessary for stable operation without membrane fouling (Navaratna and Jegatheesan 2011). After fouling had developed, the two reactors continued to be operated using the fouled membrane for approximately 1 month; during this period, the concentrated synthetic wastewater was continuously fed into MBRs to maintain the same organic loading rate. The MLSS, temperature, $\mathrm{DO}, \mathrm{pH}$, and transmembrane pressure (TMP) of the membrane module were monitored throughout the experimental period. Membrane cleaning with $0.1 \% \mathrm{NaOCl}$ was performed when required to continue MBR operation for long by reducing the foulants. Sampling of the activated sludge and the effluent (i.e., treated water) were performed at daily intervals. The obtained activated sludge samples were centrifuged $\left(15,300 \times g, 15 \mathrm{~min}\right.$, and $\left.4{ }^{\circ} \mathrm{C}\right)$ and the resulting supernatants and pellets were stored at $-20{ }^{\circ} \mathrm{C}$ separately until further analysis.

\section{$16 S$ rRNA genetic analysis}

The microbial cell pellets collected daily from the activated sludge samples were used for the microbial analyses. Genomic DNA was extracted using a direct lysis protocol that included chemical lysis, bead-beating, phenol-chloroform extraction, and ethanol precipitation (Aoyagi et al. 2015). The universal primer sets of $515 \mathrm{~F}$ and $806 \mathrm{R}$ were used to amplify the $\mathrm{V} 4$ region of $16 \mathrm{~S}$ rRNA genes with a high-fidelity DNA polymerase (Q5, NEB; Ipswich, MA, USA); both primers were modified 
to contain an Illumina adapter region and the reverse primer contained a 12-bp barcode for multiplex sequencing (Caporaso et al. 2012). The polymerase chain reaction (PCR) conditions were the same as previously described (Sato et al. 2016c), except that 30-35 cycles were performed. The PCR product was first purified with an AMPure XP kit (Beckman Coulter; Brea, CA, USA) and the target DNA fraction was isolated from the incised gel and extracted using the Wizard SV Gel and PCR CleanUp System (Promega; Madison, WI, USA). The concentration of the purified DNA was spectrophotometrically measured using a Quant-iT PicoGreen dsDNA reagent and kit (Life Technologies; Carlsbad, CA, USA) and the paired-end sequencing was conducted using a Miseq System (Illumina; San Diego, CA, USA) with a 500-cycle MiSeq reagent kit v2.

The PhiX sequences in the Illumina sequence libraries were removed using a homology search against the Greengenes database (McDonald et al. 2012). Subsequently, the obtained paired-end sequences were assembled and only high quality joined sequences (Phred value score $[\mathrm{Q}] \geq 30$ ) were collected using QIIME software version 1.7.0 (Caporaso et al. 2010). Next, these sequences were aligned by the mothur program version 1.31.2 (Schloss et al. 2009), which can also detect and exclude chimeric sequences from the library. QIIME software was used to phylogenetically analyze the sequences in each library as well as the $\alpha$-diversity indices (i.e., Chao1, Shannon, and Simpson reciprocal) and weighted UniFrac distances for the principal coordinates analysis (PCoA) analysis (Lozupone et al. 2011). The species related to the predominant operational taxonomic units (OTUs) were further determined based on a BLAST search of the NCBI database (http://blast.ncbi.nlm.nih.gov/Blast.cgi).

\section{Sodium dodecyl sulfate polyacrylamide gel electrophoresis analyses}

The extracellular proteins in the supernatants of the activated sludge were analyzed using sodium dodecyl sulfate polyacrylamide gel electrophoresis (SDS-PAGE). For these analyses, $20 \mu \mathrm{g}$ samples of the supernatants were denatured under reducing conditions by boiling them at $95{ }^{\circ} \mathrm{C}$ for $5 \mathrm{~min}$ in the sample buffer $(50 \mathrm{mM}$ Tris, $\mathrm{pH}$ $6.8,1 \%$ SDS, $2 \% \beta$-mercaptoethanol, and $0.01 \%$ bromophenol blue) and then fractionating the samples in a $13 \%$ polyacrylamide gel via electrophoresis. The proteins in the gel were visualized using fluorescent staining with Orile (Bio-Rad Laboratories; Hercules, CA, USA). The protein concentrations in the supernatants were determined using Quick Start Bradford Protein Assay kits with bovine serum albumin as the standard (Bio-Rad Laboratories) and a microplate reader (SH-9000, Corona Electric, Ibaraki, Japan) (Sato et al. 2016a).

\section{Results}

Physicochemical analyses of the pilot-scale MBRs

The operations of two 230-liter volume pilot-scale MBRs, which were designated as Reactors 1 and 2, were started with an effluent flow rate of approximately $400 \mathrm{ml} \mathrm{min}^{-1}$; this rate was five times higher than the flow rate used in previous studies conducted by our research group (Fig. 1a) (Sato et al. 2016b, c). The TMP, which indicates the requisite pressure level for membrane filtration and is a widely used indicator of membrane fouling (Le-Clech 2010; Navaratna and Jegatheesan 2011), increased to $20-30 \mathrm{kPa}$ in the first 4 days. Concomitant with the increase in TMP, the effluent flow rate drastically decreased to below $100 \mathrm{ml} \mathrm{min}^{-1}$. Taken together, these results indicate that membrane fouling was successfully developed by the excessively high flow rate conditions. Subsequently, the two MBRs continued to be operated for approximately one month (up to Days 31 and 27 for Reactors 1 and 2, respectively) with membrane cleaning performed on Days 15, 21, 23, and 24; recovery of the TMP and effluent flow rates were limited (Fig. 1a, i-iv).

The TOC concentrations in the two MBRs were similar, except for a spike in Reactor 2 on Days 13-17 (Fig. 1b). The average TOC concentrations on Days 0-3 were 82 and $29 \mathrm{mg} \mathrm{l}^{-1}$ in the activated sludge of Reactors 1 and 2, respectively, while those after Day 3 were 262 and $486 \mathrm{mg} \mathrm{l}^{-1}$, respectively, which implies that the sludge microorganisms were under high organic loading conditions following membrane fouling. By contrast, the average TOC concentrations in the effluent were several times lower than those in the sludge (61 and $211 \mathrm{mg}^{-1}$ in Reactors 1 and 2, respectively). Although fouled, it is possible that the membrane reduced the outflow of dissolved organic matter from the MBRs. The ammonium concentrations in the MBRs drastically increased after Day 3 and were then maintained at high levels throughout the operation; the average values were 461 and $434 \mathrm{mg} \mathrm{l}^{-1}$ in Reactors 1 and 2, respectively (Fig. 1c). Unlike the TOC values, the ammonium concentrations in the effluent were as high as those in the sludge, which indicates that the ammonium molecules passed through the fouled membrane. A similar increasing trend was observed in $\mathrm{pH}$ values, possibly due to the increase in ammonium concentrations (Fig. 1d) (Sato et al. 2016d).

The MLSS concentrations increased two-fold from Day 0 to 13 (approximately 6000 to $12,000 \mathrm{mg} \mathrm{l}^{-1}$ ) in both reactors (Fig. 1e). However, the MLSS concentration in Reactor 1 continued to increase throughout operation whereas the concentration in Reactor 2 decreased from Day 13 to 20. The DO concentrations in the two reactors were maintained at levels lower than $0.3 \mathrm{mg} \mathrm{l}^{-1}$ (Fig. 1f). 

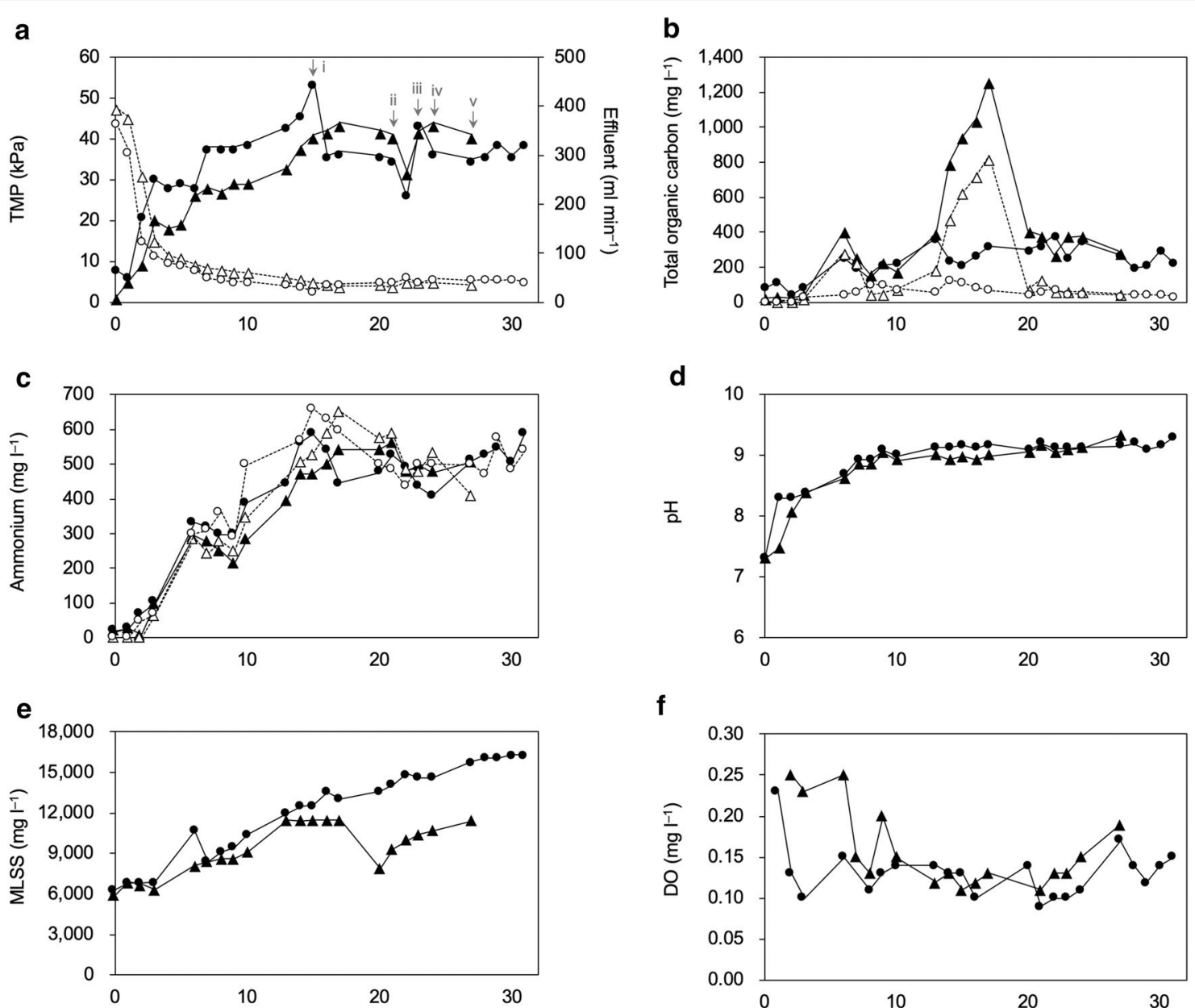

\section{f}

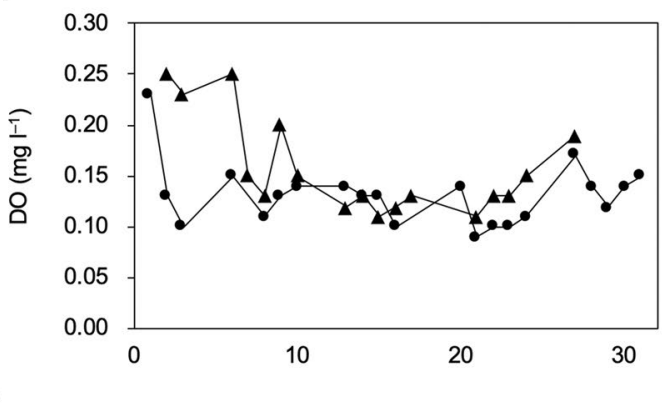

Fig. 1 Physicochemical parameters in the membrane bioreactors. a Transmembrane pressure (TMP) and effluent flow rate; b total organic carbon (TOC) concentration; $\mathbf{c}$ ammonium concentration; $\mathbf{d}$ pH; e mixed liquor suspended solids (MLSS) concentration; $\mathbf{f}$ dissolved oxygen concentration. Circles and triangles denote the data for Reactors 1 and 2, respectively, and closed and open symbols denote the data detected in the sludge and effluent, respectively. The arrows in panel A indicate the day of membrane cleaning with $0.1 \% \mathrm{NaOCl}$; (i) Cleaning was performed on Day 15 in Reactor 1 and on Days 21, 23, and 24 (ii, iii and iv) in both reactors

\section{Diversity indices of the sludge microbial communities}

The $\alpha$-diversity indices (i.e., Chao 1 and Simpson reciprocal) of the sludge microbial communities in Reactors 1 and 2 showed essentially similar trends (Fig. 2a, b). Both the Chaol and Simpson reciprocal indices, which primarily denote the richness and evenness of microbial species in the community, had drastically decreased at Day 9 and then maintained low levels during operation. These results suggest that large numbers of microbial species were washed out during operation under the high organic loading conditions and that only small numbers of microorganisms dominated the sludge microbial communities. The similarity of the microbial community structures in the two reactors was compared with a
PCoA scatter plot (Fig. 2c). On Day 4, the microbial communities in the two reactors were stable and similar to each other and, even after the development of membrane fouling, the two microbial communities showed similar structural shifts on Days 6-10. However, after Day 10, the community structures appeared to largely differ from one another despite the same operational conditions.

\section{Compositional changes of the microbial communities at the class and genus levels}

The compositional changes of the microbial communities that occurred throughout operation of the MBRs were analyzed using QIIME software (Fig. 3a-d). On Day 4, the microbial community structures in the two reactors 

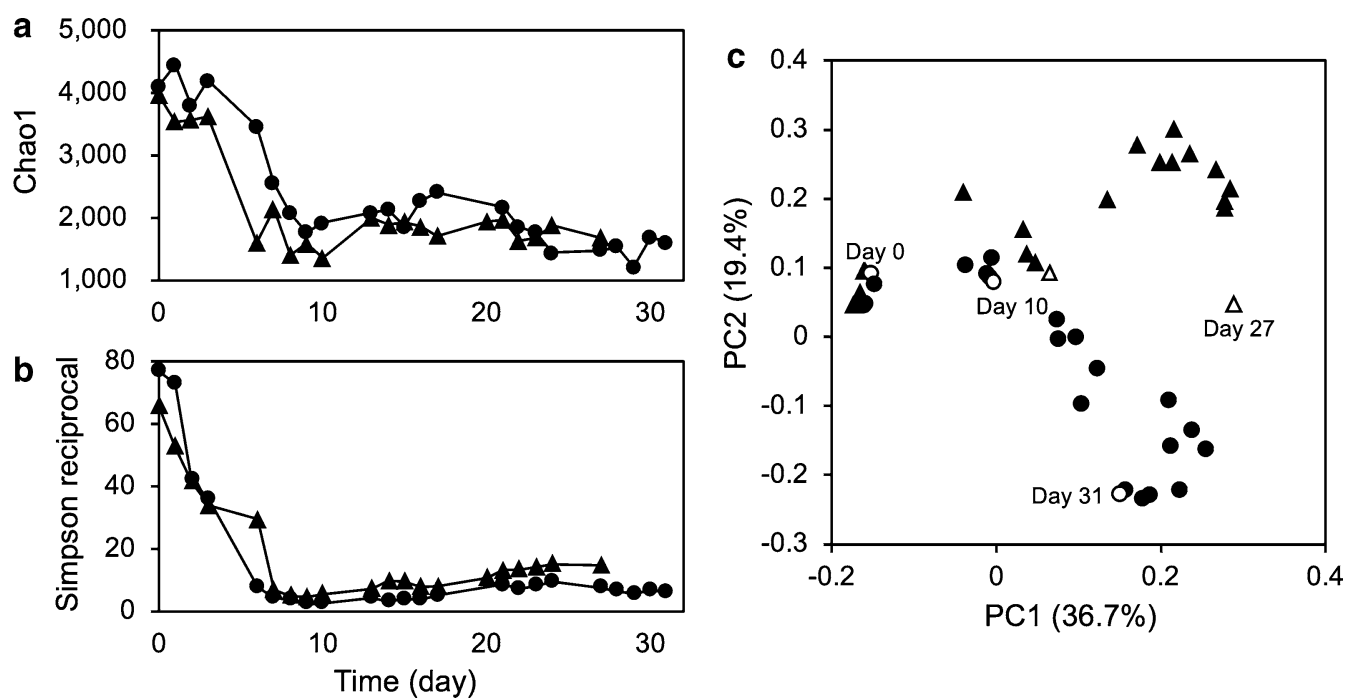

Fig. 2 Alpha-diversity indices and the PCoA plot based on the sequence data. a Chao1; $\mathbf{b}$ simpson reciprocal. Each index was calculated based on an equal amount of sequences (19,218 and 14,598 for Reactors 1 and 2, respectively) that were sub-sampled from the original libraries 10 times. For each index, a higher value represents a more diverse microbial community. c PCoA scatter plot of 16S rRNA sequences based on the weighted UniFrac distances. Circles and triangles denote Reactors 1 and 2, respectively

were similar and relatively stable and, even after the development of membrane fouling (i.e., at Days 6-10), the two microbial communities showed similar structural changes in which a genus belonging to Betaproteobacteria highly dominated the sludge microbial community (Fig. 3a-d). However, the two sludge communities exhibited distinct structural shifts after Day 10; the series of structural changes corresponded well with the results of the PCoA plot (Fig. 2c). Concomitant with the decrease in the abundance of Betaproteobacteria, there was a predominance of Alphaproteobacteria and an unidentified class in the microbial community in Reactor 1 while Clostridia and Bacteroidia predominated the microbial community in Reactor 2 (Fig. 3a, b).

\section{Phylogenetic analysis of the dominant OTUs}

The detailed phylogenetic information and relative abundances of the 10 most common OTUs in the two reactors are summarized in Fig. 4. The first structural shifts in the microbial communities in the two reactors were similar at the OTU level (Days 6-10) such that OTU1 highly predominated the sludge microbiome; the relative abundances in Reactors 1 and 2 were $~ 63 \%$ at Day 10 and $\sim 46 \%$ at Day 9 , respectively. The closest relative of this OTU was Collimonas fungivorans, which is capable of feeding on living fungal hyphae by secreting lytic enzymes (e.g., chitinase, peptidase, and phospholipase) and/or antimicrobial secondary metabolites (Song et al. 2015). Although OTU1 did not appear to actually be Collimonas fungivorans because its sequence identity was
$95 \%$, it might have possessed a similar ability to eliminate competing microorganisms. Regardless, the predominance of Collimonas fungivorans appeared to suppress the predomination of other microorganisms and resulted in precipitous declines in the evenness of the microbial communities in the two reactors.

After Day 10, phylogenetically distinct microorganisms predominated the sludge microbiomes of the respective reactors; i.e., OTUs 2, 3, 4, 5, 6, and 8 in Reactor 1 and OTUs $5,11,13,15$, and 16 in Reactor 2 . The species related to OTUs 2, 3, 4, 5, 6, and 8 were Defluviimonas alba (with a sequence identity of 99\%), Fluviicola sp. N26 (100\%), Comamonas serinivorans (100\%), Deferrisoma palaeochoriense (83\%), Aliifodinibius sp. HME9836 (88\%), and Petrimonas mucosa (94\%), respectively. Defluviimonas alba is an aerobe capable of using oxygen as the terminal electron acceptor whereas most Defluviimonas species are facultative anaerobes that are also capable of nitrate respiration (Zhao et al. 2016). Fluviicola spp. are basically aerobic but it has been reported that one species is weakly positive for nitrate reduction (Yang et al. 2014). Comamonas serinivorans is a facultative anaerobe capable of nitrate reduction (Zhu et al. 2014). Petrimonas mucosa is a facultative anaerobe that uses fermentation under anaerobic conditions (Hahnke et al. 2016). OTUs 5 and 6 seemed phylogenetically distinct from previously described microorganisms (sequence homologies with most of the related species were $<90 \%$ ).

The species related to OTUs 5, 11, 13, 15, and 16 (the dominant OTUs in Reactor 2) were Deferrisoma 


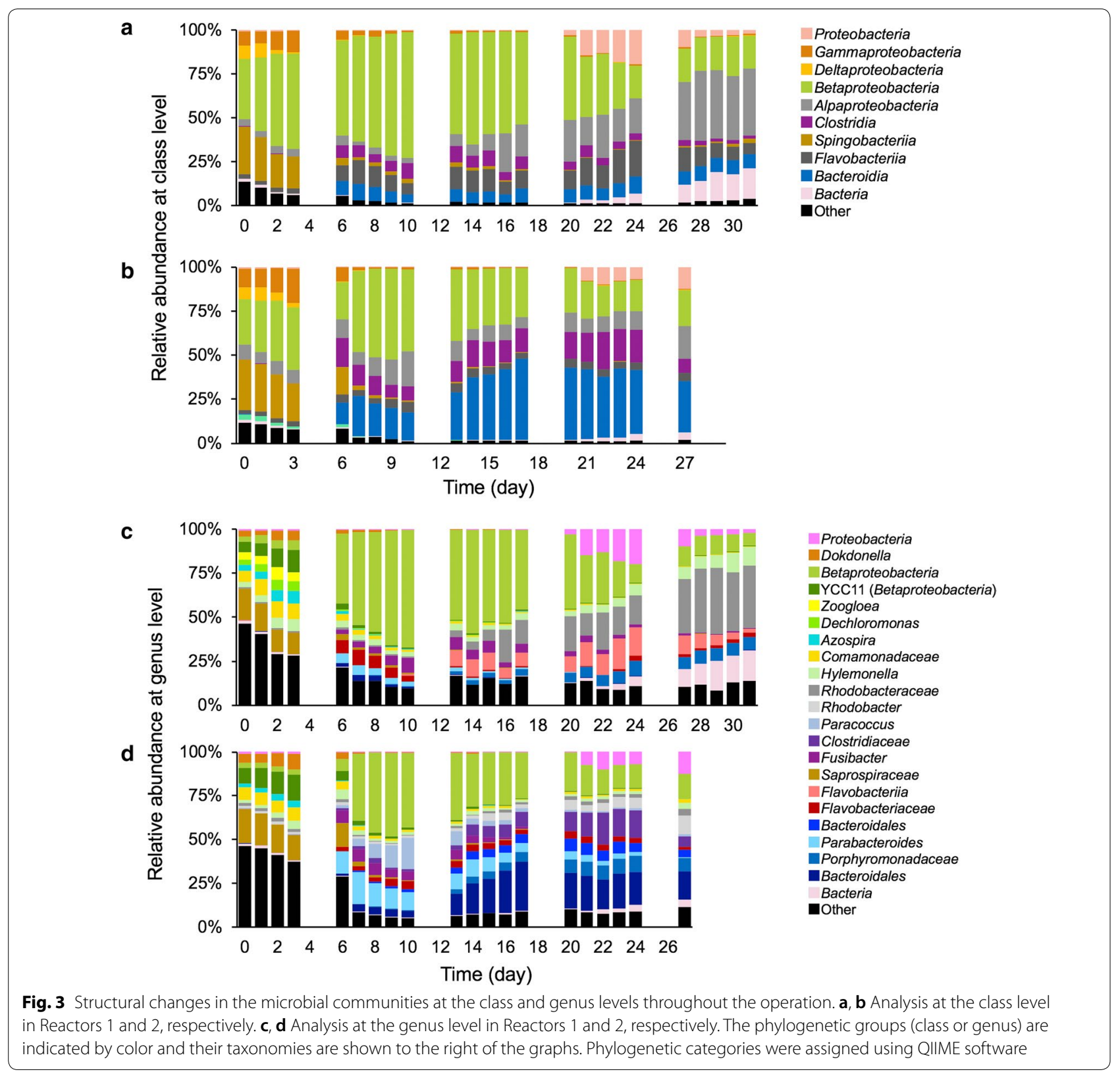

palaeochoriense (with a sequence identity of 83\%), Labilibacter aurantiacus (88\%), Tissierella praeacuta (99\%), Rhodobacter blasticus (100\%), and Macellibacteroides fermentans (94\%), respectively. Tissierella praeacuta is an obligate anaerobe but its usage of terminal electron acceptors remains unclear (Collins and Shah 1986), while, some species belonging to this genus have been reported to utilize proteinaceous substrates for their growth in anaerobic digestion processes (Nolla-Ardevol et al. 2015). Rhodobacter blasticus is an aerobic photosynthetic bacterium while Macellibacteroides fermentans is an obligate anaerobe that uses anaerobic fermentation (Brosché et al. 1998; Jabari et al. 2012).

\section{Extracellular proteins in the activated sludge}

The concentration and size distribution profiles of the extracellular proteins in the supernatant of the activated sludge were analyzed using spectrophotometric measurements and SDS-PAGE, respectively (Fig. 5). The extracellular protein concentrations were higher in the activated sludge supernatants than in the effluent in both reactors, which indicates that a majority of the extracellular proteins did not pass through the 


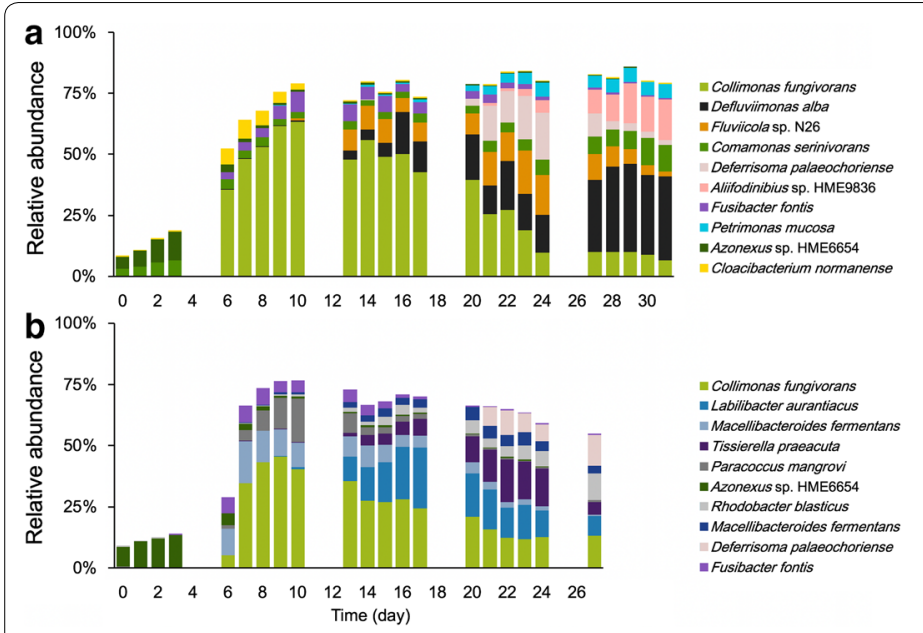

\begin{tabular}{|c|c|c|c|c|}
\hline & Related species & Identity & Accession & Class \\
\hline$\overline{\text { OTU1 }}$ & Collimonas fungivorans & $95 \%$ & KM604833.1 & Betaproteobacteria \\
\hline OTU2 & Defluviimonas alba & $99 \%$ & CP012661.1 & Alphaproteobacteria \\
\hline OTU3 & Fluviicola sp. N26 & $100 \%$ & KT004384.1 & Flavobacterïa \\
\hline OTU4 & Comamonas serinivorans & $100 \%$ & CP021455.1 & Betaproteobacteria \\
\hline OTU5 & Deferrisoma palaeochoriense & $83 \%$ & NR_148581.1 & - \\
\hline OTU6 & Aliffodinibius sp. HME9836 & $88 \%$ & KJ206439.1 & - \\
\hline OTU7 & Fusibacter fontis & $99 \%$ & NR_137378.1 & Clostridia \\
\hline OTU8 & Petrimonas mucosa & $94 \%$ & LT608328.1 & Bacteroidia \\
\hline OTU9 & Azonexus sp. HME6654 & $100 \%$ & HM590828.1 & Betaproteobacteria \\
\hline OTU10 & Cloacibacterium normanense & $100 \%$ & CP034157.1 & Flavobacteriia \\
\hline & Related species & Identity & Accession & Class \\
\hline$\overline{\text { OTU1 }}$ & Collimonas fungivorans & $95 \%$ & KM604833.1 & Betaproteobacteria \\
\hline OTU11 & Labilibacter aurantiacus & $88 \%$ & NR_156071.1 & Bacteroidia \\
\hline OTU12 & Macellibacteroides fermentans & $100 \%$ & MF800883.2 & Bacteroidia \\
\hline OTU13 & Tissierella praeacuta & $99 \%$ & NR_044860.1 & Clostridia \\
\hline OTU14 & Paracoccus mangrovi & $100 \%$ & MH915484.1 & Alphaproteobacteria \\
\hline отU9 & Azonexus sp. HME6654 & $100 \%$ & HM590828.1 & Betaproteobacteria \\
\hline OTU15 & Rhodobacter blasticus & $100 \%$ & KC295211.1 & Alphaproteobacteria \\
\hline OTU16 & Macellibacteroides fermentans & $94 \%$ & KY065448.1 & Bacteroidia \\
\hline OTU5 & Deferrisoma palaeochoriense & $83 \%$ & NR_148581.1 & - \\
\hline OTU7 & Fusibacter fontis & $99 \%$ & NR_137378.1 & Clostridia \\
\hline
\end{tabular}

Fig. 4 Transition of the 10 most dominant operational taxonomic units (OTUs) throughout the operation. Microbial community structures and phylogenetic information in Reactors 1 (a) and 2 (b). The phylogenetic information of each OTU is shown in the table on the right. The related species of the OTUs were assigned using a BLAST analysis (https://blast.ncbi.nlm.nih.gov/Blast.cgi) and the phylogenetic categories at a class level were assigned using QIIME software
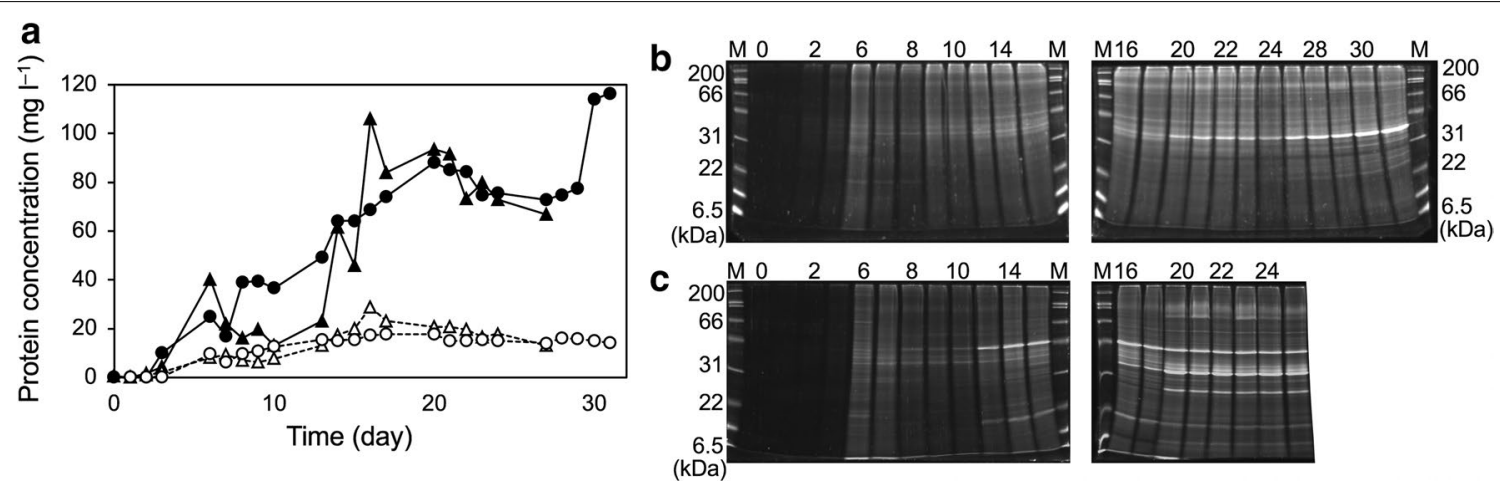

Fig. 5 Extracellular protein concentration and size distribution profiles in the activated sludge supernatants. a Protein concentrations in the sludge supernatants (closed symbols) and the effluent (open symbols). Circles and triangles denote Reactors 1 and 2, respectively. b, c SDS-PAGE analyses of the supernatants of the activated sludge in Reactors 1 and 2, respectively. Labels on the top denote operational days or size maker (M). Labels on the left denote size of the marker proteins

membrane unit and remained in the activated sludge (Fig. 5a). Notably, the protein concentrations sharply increased on Days 13-17 in Reactor 2 (Fig. 5a), which corresponded to the trend of TOC levels in the same reactor (Fig. 1b). Furthermore, sharp protein bands appeared within the same time period with SDS-PAGE analysis of Reactor 2, which indicates that the proteins were secreted out of the microbial cells rather than leaked from damaged cells (Fig. 5b, c).

\section{Discussion}

The two MBRs were operated with the fouled membrane for around 1 month. Even though the membrane fouling had been developed, TOC removal ratio was relatively high during the operation (94.6\% and $81.3 \%$ in Reactor 1 and 2, respectively, on average), whereas the nitrogen removal rate was quite low (Fig. 1b, c). Under the high organic loading conditions after the development of membrane fouling, DO level in the sludge was low (Fig. 1f), even though the activated sludge was continuously aerated throughout the operation. This indicates that there was a high demand for electron acceptors in the activated sludge under high organic loading conditions (Navarro et al. 2016; Sato et al. 2019), while electron donors (i.e., organic compounds in synthetic wastewater, such as peptone) were abundantly available.

The PCoA analysis suggests that the development of membrane fouling initially induced similar structural 
shifts in the two microbial communities (Fig. 2c; Days 6-10) but then the sludge microbial communities underwent further structural changes in divergent direction due to respective environmental factors. This finding indicates the presence of strong pressure to perturb the microbiomes under high organic loading conditions (Sato et al. 2019). The phylogenetic analyses demonstrated that class Betaproteobacteria (mainly OTU1) once highly dominated in the both reactors (Fig. 3a, b); this predominance is corresponded to decrease in the diversity indices (Fig. 2a, b) and shift in PCoA plot on Days 6-10 (Fig. 2c). However, after Day 10, Reactor 1 was predominated by Alphaproteobacteria and unidentified class, whereas Clostridia and Bacteroidia predominated in Reactor 2 (Fig. 3a, b). Notably, Alphaproteobacteria are mainly composed of aerobes and facultative anaerobes whereas Clostridia and Bacteroidia are mainly composed of obligate anaerobes.

The 10 most abundant OTUs in Reactor 1 were aerobes or facultative anaerobes, rather than obligate anaerobes. By contrast, the dominant OTUs in Reactor 2 were strictly aerobes or obligate anaerobes that use anaerobic fermentation. These results suggest that oxygen was an important and a commonly used terminal electron acceptor in both reactors, possibly because aerobic respiration is the most efficient strategy for generating adenosine triphosphate (ATP). The next most efficient ATP generating strategy involves nitrate reduction (Orcutt et al. 2011). The nitrate concentrations in the two reactors were below detection limits after Day 2 (Additional file 1: Fig. S1A), indicating the importance of nitrate as the terminal electron acceptor under low oxygen conditions in both reactors while the denitrifiers did not predominate in Reactor 2 (Fig. 4b). By contrast, there were obvious differences in sulfate concentrations between the two reactors (Additional file 1: Fig. S1B) such that the sulfate concentration in Reactor 1 increased after Day 20 whereas it was below the detection limit in Reactor 2 , which implies that sulfate was preferably required for the microbiome in Reactor 2 but not in Reactor 1. Even though sulfate-reducing bacteria were not found among the dominant OTUs, other low-abundance microorganisms in Reactor 2 might have used sulfate as an electron acceptor. Besides, the abundances of nitrifiers, i.e., ammonia oxidizing bacteria and nitrite oxidizing bacteria, at Day 1-4 were apparently high in Reactor 1 than in Reactor 2 (Additional file 1: Fig. S2). Low level of nitrate production from ammonia might allow the microbiome in Reactor 2 to preferably utilize the other terminal electron acceptors, such as sulfate, in the anaerobic environments possibly existing locally in the activated sludge.

To further investigate the factors caused the difference in microbial community structures, a particular focus was placed on extracellular proteins because on Days 13-17 during which the structural shifts in the two microbial communities appeared to begin, the extracellular protein concentration sharply increased while the MLSS value decreased in only Reactor 2 (Figs. 1e and 4a). Because some microorganisms express extracellular lytic enzymes to compete for survival in complex microbial communities (Lakshmi et al. 2014), the extracellular proteins observed in the SDSPAGE analyses might have had such functions. The fact that the MLSS concentration in Reactor 2 decreased in the same time period may support this hypothesis. To identify the proteins, the supernatants of the activated sludge were fractionated using fast protein liquid chromatography with an ion exchange column. Although one of the five proteins detected in the SDS-PAGE analyses was successfully purified, neither N-terminal amino acid sequencing using a protein sequencer nor an ion search using nano-liquid chromatography tandem mass spectrometry could identify any proteins (data not shown). To figure out the effect of the extracellular proteins on the microbial community in Reactor 2, the OTUs whose relative abundance highly increased on Days 10-20, in which the protein concentration increased and the MLSS value decreased, were summarized in Additional file 1: Table S1. Notably, 11 of the 20 OTUs were affiliated within Bacteroidia; all of these species are fermentative anaerobes (including facultative and obligately ones) that can utilize organic substances to generate ATP under anaerobic conditions (Grabowski et al. 2005; Jabari et al. 2012). The decrease in MLSS value and the increase in TOC and protein concentrations on Days 10-20 suggested that, during this time period, abundant biomolecules were discharged from the damaged microbial cells. Such environment seemed advantageous for anaerobic fermentative microorganisms, possibly allowing the predominance of the 11 Bacteroidia OTUs in Reactor 2.

In conclusion, the present study observed the dynamic transition of sludge microbial communities under high organic loading conditions following the induction of membrane fouling, which is an issue that has yet to be fully investigated. One disadvantage associated with wastewater treatment that is caused by extreme conditions may be the excessive predomination of limited numbers of OTUs because this type of predominance can reduce the diversity of a sludge microbiome and subsequently decrease adaptability to environmental changes (Loreau et al. 2003). Therefore, monitoring microbial diversity during the operation of activated sludge bioreactors might be a valuable indicator for maintaining the robustness of a sludge microbiome. On the other hand, the microbial communities in the two reactors initially 
showed similar structural shifts but underwent additional changes in different directions even though the two reactors were operated under the same conditions. The microbial community structures seemed to be shaped basically by the availability of terminal electron acceptors. Further, spike in concentration of organic compound appeared to facilitate predominance of anaerobic fermentative microorganisms and changed the community structure of Reactor 2.

\section{Supplementary information}

Supplementary information accompanies this paper at https://doi. org/10.1186/s13568-020-0959-2.

Additional file 1: Fig. S1. a Nitrate and $\mathbf{b}$ sulfate concentrations in the effluents of Reactors 1 and 2; the values are means of two measurements. Bars indicate variations and circles and triangles denote the values for Reactors 1 and 2, respectively. Fig. S2. Relative abundances of OTUS assigned to nitrifiers in Reactors 1 (a) and 2 (b). Phylogenetic classification of the OTUs was performed using BLAST analysis (https://blast.ncbi.nlm. nih.gov/Blast.cgi). Table S1. OTUs that highly increased from day 10 to 20 in Reactor 2

\section{Acknowledgements}

We thank M. Yanagisawa, K. Matsuo and Y. Kayashima for technical supports, Kinu-aqua station for providing activated sludge.

\section{Authors' contributions}

$\mathrm{YS}, \mathrm{TH}, \mathrm{AO}$ and $\mathrm{HH}$ designed the study. YS, TH, TA, TI and HA performed reactor operation and sample collection. YS and TA performed sequencing and $Y S$ and $Z Y$ analyzed the data. YS, ZY, TH, TA and TI contributed to the interpretation of the results. YS and ZY wrote the manuscript with input from all co-authors. All authors read and approved the final manuscript.

\section{Funding}

This study was partly supported by Japan Society for the Promotion of Science KAKENHI Grant Number JP17H04716, 19 K22297 and 19K22939.

\section{Availability of data and materials}

The raw sequence data obtained in the present study have been deposited in the DNA Data Bank of Japan (DDBJ) Sequence Read Archive under accession code DRA008692.

\section{Ethics approval and consent to participate}

Not applicable.

\section{Consent for publication}

Not applicable.

\section{Competing interests}

The author declares that they have no competing interests.

Received: 12 January 2020 Accepted: 16 January 2020

Published online: 28 January 2020

\section{References}

Albertsen M, Hugenholtz P, Skarshewski A, Nielsen KL, Tyson GW, Nielsen PH (2013) Genome sequences of rare, uncultured bacteria obtained by differential coverage binning of multiple metagenomes. Nat Biotechnol 31(6):533-538. https://doi.org/10.1038/nbt.2579

Aoyagi T, Hanada S, Itoh H, Sato Y, Ogata A, Friedrich MW, Kikuchi Y, Hori T (2015) Ultra-high-sensitivity stable-isotope probing of rRNA by high-throughput sequencing of isopycnic centrifugation gradients. Environ Microbiol Rep 7(2):282-287. https://doi.org/10.1111/1758-2229.12243 Brosché M, Kalbina I, Arnfelt M, Benito G, Karlsson BG, Strid Å (1998) Occurrence, overexpression and partial purification of the protein (majastridin) corresponding to the URF6 gene of the Rhodobacter blasticus atp operon. Eur J Biochem 255:87-92. https://doi.org/10.1046/j.1432-1327.1998.25500 87.x

Caporaso JG, Kuczynski J, Stombaugh J, Bittinger K, Bushman FD, Costello EK, Fierer N, Peña AG, Goodrich JK, Gordon J, Huttley GA, Kelley ST, Knights D, Koenig JE, Ley RE, Lozupone CA, McDonald D, Muegge BD, Pirrung M, Reeder J, Sevinsky JR, Turnbaugh PJ, Walters WA, Widmann J, Yatsunenko T, Zaneveld J, Knight R (2010) QIIME allows analysis of high-throughput community sequencing data. Nat Methods 7(5):335-336. https://doi. org/10.1038/nmeth0510-335

Caporaso JG, Lauber CL, Walters WA, Berg-Lyons D, Huntley J, Fierer N, Owens SM, Betley J, Fraser L, Bauer M, Gormley N, Gilbert JA, Smith G, Knight $R$ (2012) Ultra-high-throughput microbial community analysis on the Illumina HiSeq and MiSeq platforms. ISME J 6(8):1621-1624. https://doi. org/10.1038/ismej.2012.8

Collins MD, Shah HN (1986) Reclassification of Bacteroides praeacutus Tissier (Holdeman and Moore) in a new genus, Tissierella, as Tissierella praeacuta. Int J Syst Bacteriol 36(3):461-463. https://doi.org/10.1099/00207 713-36-3-461

Grabowski A, Tindall BJ, Bardin V, Blanchet D, Jeanthon C (2005) Petrimonas sulfuriphila gen. nov., sp. nov., a mesophilic fermentative bacterium isolated from a biodegraded oil reservoir. Int J Syst Evol Microbiol 55(Pt 3):1113-1121. https://doi.org/10.1099/ijs.0.63426-0

Griffin JS, Wells GF (2017) Regional synchrony in full-scale activated sludge bioreactors due to deterministic microbial community assembly. ISME 11(2):500-511. https://doi.org/10.1038/ismej.2016.121

Hahnke S, Langer T, Koeck DE, Klocke M (2016) Description of Proteiniphilum saccharofermentans sp. nov., Petrimonas mucosa sp. nov. and Fermentimonas caenicola gen. nov., sp. nov., isolated from mesophilic laboratoryscale biogas reactors, and emended description of the genus Proteiniphilum. Int J Syst Evol Microbiol 66(3):1466-1475. https://doi.org/10.1099/ ijsem.0.000902

Inaba T, Hori T, Aizawa H, Ogata A, Habe H (2017) Architecture, component, and microbiome of biofilm involved in the fouling of membrane bioreactors. NPJ Biofilms Microbiomes 3:5. https://doi.org/10.1038/s4152 2-016-0010-1

Inaba T, Hori T, Sato Y, Aoyagi T, Hanajima D, Ogata A, Habe H (2018) Eukaryotic microbiomes of membrane-attached biofilms in membrane bioreactors analyzed by high-throughput sequencing and microscopic observations. Microbes Environ 33(1):98-101. https://doi.org/10.1264/jsme2.ME17112

Jabari L, Gannoun H, Cayol JL, Hedi A, Sakamoto M, Falsen E, Ohkuma M, Hamdi M, Fauque G, Ollivier B, Fardeau ML (2012) Macellibacteroides fermentans gen. nov., sp. nov., a member of the family Porphyromonadaceae isolated from an upflow anaerobic filter treating abattoir wastewaters. Int J Syst Evol Microbiol 62(Pt 10):2522-2527. https://doi.org/10.1099/ ijs.0.032508-0

Lakshmi MV, Merrylin J, Kavitha S, Kumar SA, Banu JR, Yeom IT (2014) Solubilization of municipal sewage waste activated sludge by novel lytic bacterial strains. Environ Sci Pollut Res Int 21(4):2733-2743. https://doi. org/10.1007/s11356-013-2228-2

Le-Clech P (2010) Membrane bioreactors and their uses in wastewater treatments. Appl Microbiol Biotechnol 88(6):1253-1260. https://doi org/10.1007/s00253-010-2885-8

Li WW, Yu HQ, Rittmann BE (2015) Chemistry: reuse water pollutants. Nature 528(7580):29-31. https://doi.org/10.1038/528029a

Loreau M, Mouquet N, Gonzalez A (2003) Biodiversity as spatial insurance in heterogeneous landscapes. Proc Natl Acad Sci U S A 100(22):1276512770. https://doi.org/10.1073/pnas.2235465100

Lozupone C, Lladser ME, Knights D, Stombaugh J, Knight R (2011) UniFrac: an effective distance metric for microbial community comparison. ISME J 5(2):169-172. https://doi.org/10.1038/ismej.2010.133

McDonald D, Price MN, Goodrich J, Nawrocki EP, DeSantis TZ, Probst A, Andersen GL, Knight R, Hugenholtz P (2012) An improved Greengenes taxonomy with explicit ranks for ecological and evolutionary analyses of bacteria and archaea. ISME J 6(3):610-618. https://doi.org/10.1038/ismej 2011.139 
Narihiro T, Nobu MK, Hori T, Aoyagi T, Sato Y, Inaba T, Aizawa H, Tamaki H, Habe $H$ (2019) Effects of the wastewater flow rate on interactions between the genus nitrosomonas and diverse populations in an activated sludge microbiome. Microbes Environ 34(1):89-94. https://doi.org/10.1264/ jsme2.ME18108

Navaratna D, Jegatheesan $V$ (2011) Implications of short and long term critical flux experiments for laboratory-scale MBR operations. Bioresour Technol 102(9):5361-5369. https://doi.org/10.1016/j.biortech.2010.12.080

Navarro RR, Hori T, Sato Y, Tanaka R, Ogata A, Habe H (2016) High susceptibility of aerobic microbiota in membrane bioreactor (MBR) sludge towards olive oil as revealed by high-throughput sequencing of $16 \mathrm{~S}$ rRNA genes. J Environ Chem Eng 4(4):4392-4399. https://doi.org/10.1016/j. jece.2016.09.037

Nolla-Ardevol V, Peces M, Strous M, Tegetmeyer HE (2015) Metagenome from a Spirulina digesting biogas reactor: analysis via binning of contigs and classification of short reads. BMC Microbiol 15:277. https://doi. org/10.1186/s12866-015-0615-1

Orcutt BN, Sylvan JB, Knab NJ, Edwards KJ (2011) Microbial ecology of the dark ocean above, at, and below the seafloor. Microbiol Mol Biol Rev 75(2):361-422. https://doi.org/10.1128/MMBR.00039-10

Sato Y, Hori T, Navarro RR, Habe H, Ogata A (2015) Effect of a microbiota activator on accumulated ammonium and microbial community structure in a pilot-scale membrane bioreactor. J Gen Appl Microbiol 61(4):132-138. https://doi.org/10.2323/jgam.61.132

Sato Y, Hori T, Habe H, Ogata A (2016a) A preliminary diagnostic method for membrane fouling using extracellular proteins secreted in pilot-scale membrane bioreactors. J Environ Biotechnol 16(1):65-68

Sato Y, Hori T, Navarro RR, Habe H, Ogata A (2016b) Functional maintenance and structural flexibility of microbial communities perturbed by simulated intense rainfall in a pilot-scale membrane bioreactor. Appl Microbiol Biotechnol 100(14):6447-6456. https://doi.org/10.1007/s0025 3-016-7466-z

Sato Y, Hori T, Navarro RR, Habe H, Yanagishita H, Ogata A (2016c) Fine-scale monitoring of shifts in microbial community composition after high organic loading in a pilot-scale membrane bioreactor. J Biosci Bioeng 121(5):550-556. https://doi.org/10.1016/j.jbiosc.2015.10.003

Sato Y, Hori T, Navarro RR, Naganawa R, Habe H, Ogata A (2016d) Effects of organic-loading-rate reduction on sludge biomass and microbial community in a deteriorated pilot-scale membrane bioreactor. Microbes Environ 31(3):361-364. https://doi.org/10.1264/jsme2.ME16015

Sato Y, Hori T, Koike H, Navarro RR, Ogata A, Habe H (2019) Transcriptome analysis of activated sludge microbiomes reveals an unexpected role of minority nitrifiers in carbon metabolism. Commun Biol 2:179. https://doi. org/10.1038/s42003-019-0418-2
Schloss PD, Westcott SL, Ryabin T, Hall JR, Hartmann M, Hollister EB, Lesniewski RA, Oakley BB, Parks DH, Robinson CJ, Sahl JW, Stres B, Thallinger GG, Van Horn DJ, Weber CF (2009) Introducing mothur: open-source, platformindependent, community-supported software for describing and comparing microbial communities. Appl Environ Microbiol 75(23):7537-7541. https://doi.org/10.1128/AEM.01541-09

Sheik AR, Muller EE, Wilmes P (2014) A hundred years of activated sludge: time for a rethink. Front Microbiol 5:47. https://doi.org/10.3389/fmicb .2014.00047

Song C, Schmidt R, de Jager V, Krzyzanowska D, Jongedijk E, Cankar K, Beekwilder J, van Veen A, de Boer W, van Veen JA, Garbeva P (2015) Exploring the genomic traits of fungus-feeding bacterial genus Collimonas. BMC Genomics 16:1103. https://doi.org/10.1186/s12864-015-2289-3

Vuono DC, Benecke J, Henkel J, Navidi WC, Cath TY, Munakata-Marr J, Spear JR, Drewes JE (2015) Disturbance and temporal partitioning of the activated sludge metacommunity. ISME J 9(2):425-435. https://doi.org/10.1038/ ismej.2014.139

Wang Z, Wu Z, Tang S (2009) Extracellular polymeric substances (EPS) properties and their effects on membrane fouling in a submerged membrane bioreactor. Water Res 43(9):2504-2512. https://doi.org/10.1016/j.watre s.2009.02.026

Wu L, Ning D, Zhang B, Li Y, Zhang P et al (2019) Global diversity and biogeography of bacterial communities in wastewater treatment plants. Nat Microbiol. https://doi.org/10.1038/s41564-019-0426-5

Xia Y, Wen X, Zhang B, Yang Y (2018) Diversity and assembly patterns of activated sludge microbial communities: a review. Biotechnol Adv 36(4):1038-1047. https://doi.org/10.1016/j.biotechadv.2018.03.005

Yang HX, Wang X, Liu XW, Zhang J, Yang GQ, Lau KW, Li SP, Jiang JD (2014) Fluviicola hefeinensis sp. nov., isolated from the wastewater of a chemical factory. Int J Syst Evol Microbiol 64(Pt 3):700-704. https://doi.org/10.1099/ iis.0.056705-0

Zhao JY, Geng S, Xu L, Hu B, Sun JQ, Nie Y, Tang YQ, Wu XL (2016) Complete genome sequence of Defluviimonas alba cai42(T), a microbial exopolysaccharides producer. J Biotechnol 239:9-12. https://doi.org/10.1016/j. jbiotec.2016.09.017

Zhu D, Xie C, Huang Y, Sun J, Zhang W (2014) Description of Comamonas serinivorans sp. nov., isolated from wheat straw compost. Int J Syst Evol Microbiol 64(Pt 12):4141-4146. https://doi.org/10.1099/ijs.0.066688-0

\section{Publisher's Note}

Springer Nature remains neutral with regard to jurisdictional claims in published maps and institutional affiliations.

\section{Submit your manuscript to a SpringerOpen ${ }^{\circ}$ journal and benefit from:}

- Convenient online submission

- Rigorous peer review

- Open access: articles freely available online

- High visibility within the field

- Retaining the copyright to your article

Submit your next manuscript at $\boldsymbol{\nabla}$ springeropen.com 